\title{
Comparison of Nutritional Compositions and Essential Oil Profiles of Different Parts of a Dill and Two Fennel Cultivars
}

\author{
Yuanpeng Hao ${ }^{1,2} \mathbb{D}$, Jiamu Kang ${ }^{3}$, Xiaoqi Guo ${ }^{1,2}$, Rui Yang ${ }^{1,2}$, Yuliang Chen ${ }^{4}$, Jingyi Li ${ }^{1,+}$ and Lei Shi ${ }^{1, *,+}$ \\ 1 Key Laboratory of Plant Resources and Beijing Botanical Garden, Institute of Botany, \\ Chinese Academy of Sciences, Beijing 100093, China; yphao@ibcas.ac.cn (Y.H.); guoxiaoqi@ibcas.ac.cn (X.G.); \\ yangrui1993@ibcas.ac.cn (R.Y.); jingyileesd@126.com (J.L.) \\ 2 University of Chinese Academy of Sciences, Beijing 100049, China \\ 3 College of Food Science \& Nutritional Engineering, China Agricultural University, Beijing 100083, China; \\ Jiamu_kang@163.com \\ 4 Institute of Biotechnology, Gansu Academy of Agricultural Sciences, Lanzhou 730070, China; \\ cheny1925@163.com \\ * Correspondence: shilei_67@126.com \\ + These authors contributed equally to this work.
}

Citation: Hao, Y.; Kang, J.; Guo, X.;

Yang, R.; Chen, Y.; Li, J.; Shi, L.

Comparison of Nutritional

Compositions and Essential Oil Profiles of Different Parts of a Dill and Two Fennel Cultivars. Foods 2021, 10, 1784. https://doi.org/10.3390/ foods10081784

Academic Editor: Rubén Domínguez

Received: 28 June 2021

Accepted: 29 July 2021

Published: 31 July 2021

Publisher's Note: MDPI stays neutral with regard to jurisdictional claims in published maps and institutional affiliations.

Copyright: (c) 2021 by the authors. Licensee MDPI, Basel, Switzerland. This article is an open access article distributed under the terms and conditions of the Creative Commons Attribution (CC BY) license (https:/ / creativecommons.org/licenses/by/ $4.0 /)$.
Abstract: Fennel and dill are widely used as food additives owing to their various biological activities, such as antioxidants, antimicrobials, food-preservatives, and seasoning capacities. Herein, the nutritional composition and essential oil (EO) chemical profiles of fruits, umbels, stalks, and roots from one dill and two fennel cultivars were evaluated. The fruits had the highest content of crude protein $(\geq 15 \%)$, crude fat $(\geq 8 \%)$, and phosphorus $(\geq 0.5 \%)$, and exhibited the highest total energy ( $\geq 20 \mathrm{MJ} / \mathrm{kg})$ and EO yield $(\geq 2 \%)$. Moreover, estragole $(86.56 \%$ in Fdf), anethole $(71.17 \%$ in Fhf), fenchone (16.74\% in Fhf), limonene (50.19\% in Agf), and carvone (42.41\% in Agf) were the main components of the EOs generated from the fruits. The chemical profiles of EOs in the roots were significantly different from those of the aerial parts of the fennel and dill; thus, the roots and aerial parts could be distinguished based on myristicin (Variable Importance in Projection $(\mathrm{VIP})=1.90399)$ and apiol (VIP = 1.85922). The EO components of the aerial parts varied remarkably, and the chemical markers for differentiating these three cultivars were anethole (VIP = 1.36571), estragole (VIP = 1.30292), and carvone (VIP = 1.11947). Overall, our results provide a noteworthy chemical basis for further development of fennel and dill, especially as food additives.

Keywords: Apiaceae plants; plant parts; efficient utilization; multivariate analysis; food additives

\section{Introduction}

The Apiaceae plant family comprises some of the most important medicinal and aromatic plants cultivated worldwide [1]. Fennel (Foeniculum vulgare Mill.) and dill (Anethum graveolens L.) are the most vital medicinal and aromatic plants in the Apiaceae family [2], as they are rich in fatty and amino acids, fiber, minerals, vitamins, flavonoids, phenols, and volatile components. Consequently, fennel and dill are useful for obtaining stomachic, galactagogue, carminative, and mildly diuretic substances [3-6]. Moreover, they are industrially and economically valuable herbs [7,8].

Fennel and dill fruits can be eaten as a condiment because of their unique flavor and abundant nutritional profile [9]. Furthermore, fennel is an excellent plant-based source of potassium, sodium, phosphorus, and calcium [10]. The nutritional composition of different parts of such plants varies; for example, the mineral content of fennel leaves is higher than that of fennel fruits [11]. Minerals play an important role in animal reproduction and are vital for healthy growth. For instance, to meet the need for milk synthesis after childbirth, the demand for calcium increases during lactation. Many important enzymes also require trace minerals, which are vital for enzymatic and structural functions [12]. Therefore, fennel and dill by-products can also be used as feed additives to promote the healthy growth 
of animals, increase gastrointestinal (GI) peristalsis and intake, and improve intestinal microorganism balance [13,14].

Consumer preference for clean-label products requires the food industry to reformulate products by replacing artificial additives, such as colors, flavors, and preservatives, with natural alternatives [15]. Essential oils (EOs) are a complex mixture of secondary metabolites (terpenes, phenolic compounds, and alcohols) that can be extracted from several parts of medicinal and aromatic plants. EOs exhibit extensive biological activities, including antioxidant, antimicrobial, and anti-inflammatory activities [16]. In particular, fennel and dill EOs have a distinctive flavor and possess antibacterial and food preservation capabilities. Thus, there is substantial potential for the application of such oils in the food industry. Notably, these oils are generally recognized as safe (GRAS) substances and have the potential to be used as food additives for vegetables, fruits, baked goods, meat, and dairy products [17-19]. Certain EO components from fennel and dill are used in the food, biopesticide, and pharmaceutical industries. For instance, carvone was identified as an effective potato sprout inhibitor [20] that accounts for the flavor and antiflatulence characteristics of dill [8]. Furthermore, limonene possesses a pleasant lemon flavor and is used as an antibacterial additive in common foods (e.g., fruit juices, sweets, and ice cream), and it is easily digested and absorbed by the GI tract [21,22].

Many studies have focused on the biological activities of fennel and dill. However, a lack of systematic studies on fundamental chemical information currently limits the application of these plants. Thus, given the immense nutritional value and wide range of biological activities of fennel and dill, this study aimed to investigate the chemical diversity of different parts of the plants and cultivar species. The nutritional composition and EO chemical profiles of different parts of locally grown fennel and dill species were measured. Moreover, a multidimensional exploration regarding EOs was performed in this study. The detailed chemical characterization of different parts of fennel and dill plants will provide baseline data to guide their application as food additives.

\section{Materials and Methods}

\subsection{Sample Collection and Preparation}

Two fennel cultivars of Foeniculum vulgare "Dwarf" (Fd) and Foeniculum vulgare "High" (Fh), and one dill cultivar of Anethum graveolens (Ag), were collected from Minqin County in Gansu Province, where the climate is temperate, continental, and arid. The studied plants were grown on soft and sandy soils, and these cultivars were commercially available. Thirty individual samples of each plant were wholly (including roots) harvested at dawn between September and October 2018 and stored at room temperature $\left(20-25^{\circ} \mathrm{C}\right)$. Each plant was divided into four parts: fruit, umbel, stem, and root. Abbreviations corresponding to a total of twelve samples are as follows: Fd fruit (Fdf), Fd umbel (Fdu), Fd stem (Fds), Fd root (Fdr), Fh fruit (Fhf), Fh umbel (Fhu), Fh stem (Fhs), Fh root (Fhr), Ag fruit (Agf), Ag umbel (Agu), Ag stem (Ags), Ag root (Agr).

\subsection{Determination of Nutritional Composition from Plant Materials}

Dry matter, ash, phosphorus, and calcium contents were determined according to the AOAC procedures [23]. Acid detergent fiber (ADF) and neutral detergent fiber (NDF) were determined using heat-stable $\alpha$-amylase and sodium sulfite [24]. The total energy was determined using a parr-6400 oxygen bomb calorimeter. A Kjeltec ${ }^{\text {TM }}$ Sampler8420 Automatic Kjeldahl nitrogen analyzer (FOSS) was used to measure the crude protein content. Total fat was measured using an $\mathrm{ANKOM}^{\mathrm{XT15}}$ automatic fat analyzer.

\subsection{Extraction and Yield Determination of EOs}

Air-dried samples were ground and subjected to steam distillation using a Clevengertype apparatus for $3 \mathrm{~h}$ (100 g sample: $1000 \mathrm{~mL}$ water). The isolated EOs were dried over anhydrous sodium sulfate and stored at $4{ }^{\circ} \mathrm{C}$ in an amber bottle before gas chromatography- 
mass spectrometry (GC-MS) analysis. The EO yields were estimated based on the dry weight of the plant materials (in $\% v / w$ for $100 \mathrm{~g}$ of dried raw material).

\subsection{Gas Chromatography-Mass Spectrometry (GC-MS) Analysis}

The EOs were filtered and diluted in $n$-hexane at a ratio of 1:200. These samples were then detected via GC-MS (7890A-7000B, Agilent Technologies, Santa Clara, CA, USA) analysis with an HP-5MS column ( $30 \mathrm{~m} \times 250 \mu \mathrm{m} \times 0.25 \mu \mathrm{m}$; Agilent Technologies). The injector temperature was $250{ }^{\circ} \mathrm{C}$. The oven program was conducted as follows: $1 \mu \mathrm{L}$ of the sample was injected in a 100:1 split mode. The temperature was maintained at $40{ }^{\circ} \mathrm{C}$ for $2 \mathrm{~min}$, and the linear ramp reached $152{ }^{\circ} \mathrm{C}$ at a rate of $4{ }^{\circ} \mathrm{C} \cdot \mathrm{min}^{-1}$; the second ramp attained $310^{\circ} \mathrm{C}$ at a rate of $100{ }^{\circ} \mathrm{C} \cdot \mathrm{min}^{-1}$. The mass spectrometry conditions were set as follows: ionization energy, $70 \mathrm{eV}$; electronic impact ion source temperature, $230{ }^{\circ} \mathrm{C}$; quadrupole temperature, $150{ }^{\circ} \mathrm{C}$; and mass range, $40-700 \mathrm{u}$. The EO compounds were identified by comparing the National Institute of Standards and Technology (NIST) 17 library spectra and the retention index (RI) [25]. The RI values were determined using n-alkane (C7-C40) hydrocarbons under the same conditions. The chemical profiles of the EOs were obtained from the corresponding peak areas.

\subsection{Statistical Analysis}

Variance analysis was performed to evaluate the significance of differences using SPSS software (IBM SPSS 25.0; SPSS Inc., Chicago, IL, USA) and results with $p$ values $<0.05$ were considered significant. Heatmaps, Spearman's rank correlation analysis $(p<0.05)$ results, UpSet plots, Venn diagrams, and principal component analysis (PCA) plots were obtained using the $\mathrm{R}$ platform. To further distinguish the differences and relationships among EOs, supervised statistical data treatment was performed using OPLS-DA by SIMCA (Version 14.1, Umetrics, Umea, Sweden).

\section{Results and Discussion}

\subsection{Morphological Observations}

As shown in Figure 1, the fruits of Fd and Fh were plump and shared a similar shape (ridged and oblong to ovoid), size (1.5-2.5 mm broad; 4-6 mm long), and coloring of the fruit epidermis (green). By contrast, the fruits of Ag were oblate, with a smaller size (1-2 mm broad; $2-4 \mathrm{~mm}$ long), and a brown epidermis. The fruits of $\mathrm{Fd}, \mathrm{Fh}$, and $\mathrm{Ag}$ were cremocarps, comprising a pair of symmetrical carpels (Figure 1C,I,O). The EOs were distributed in the oil ducts, which were oval or semicircular. Six oil ducts exist in the fixation locations of cremocarps. Upon detailed examination, we observed a side groove in each of the two strong ribs, and four oil ducts were located under the side groove, and two additional oil ducts were located on the ventral side. On short pedicels of each umbel section, 10-50 fruits were present (Figure 1D,J,P). The stalks of Fd, Fh, and Ag were smooth, bright green, cylindrical, and erect (Figure 1E,K,Q). The roots of Fd, Fh, and Ag also shared similar cylindrical shapes and sizes, with colors ranging from white to brown. 

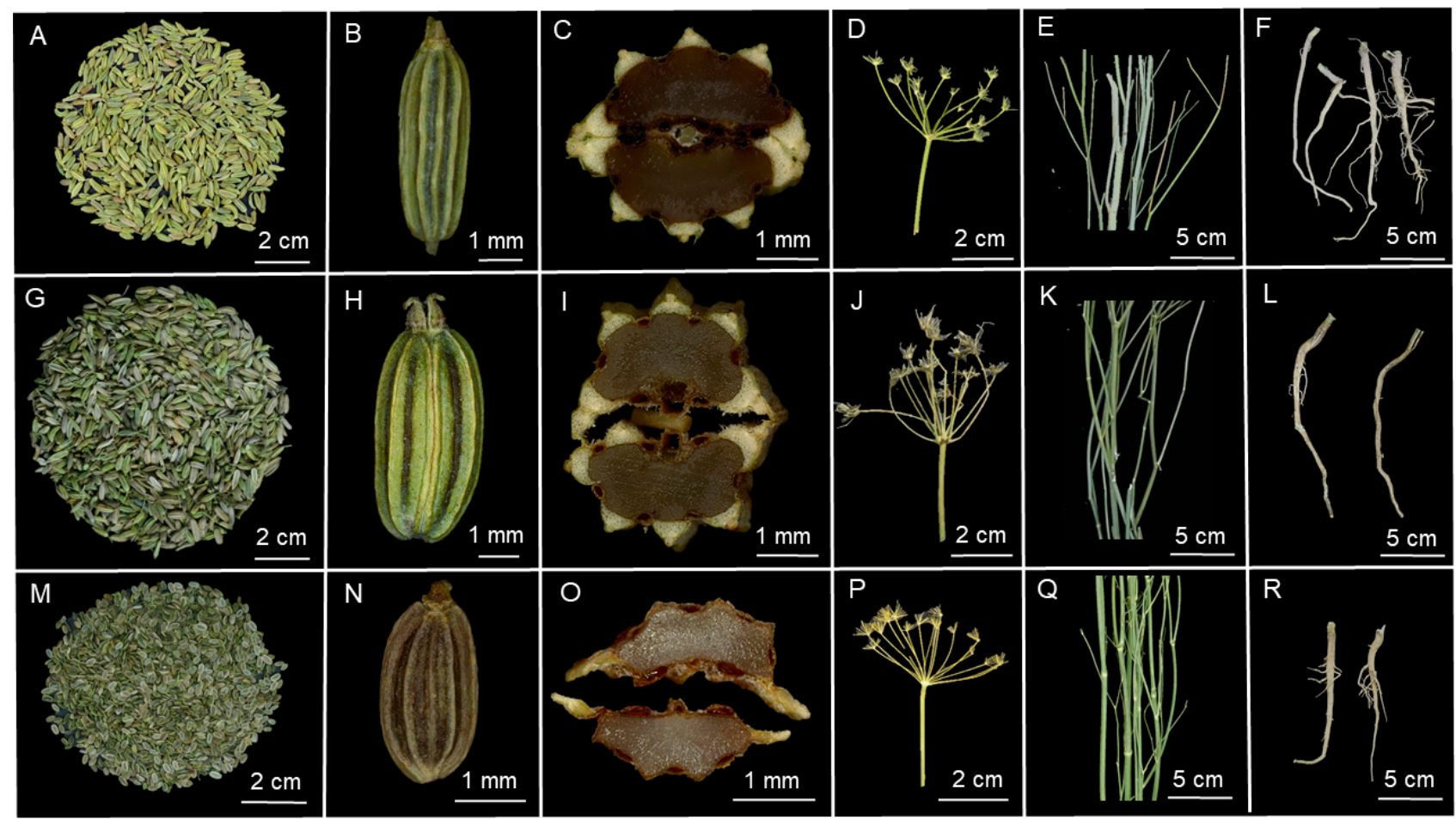

Figure 1. Representative images of different parts of one dill and two fennel cultivars. (A-C) Foeniculum vulgare "Dwarf" fruit (Fdf); (D) F. vulgare “Dwarf" umbel (Fdu); (E) F. vulgare “Dwarf" stalk (Fds); (F) F. vulgare "Dwarf” $\operatorname{root}(\mathrm{Fdr}) ;(\mathrm{G}-\mathrm{I}) F$. vulgare "High" fruit (Fdf); (J) F. vulgare "High" umbel (Fhu); (K) F. vulgare "High" stalk (Fhs); (L) F. vulgare "High" root (Fhr); (M-O) Anethum graveolens fruit (Agf); (P) A. graveolens umbel (Agu); (Q) A. graveolens stalk (Ags); (R) A. graveolens $\operatorname{root}(\mathrm{Agr})$.

\subsection{Analysis of Nutritional Compositions}

Species-related factors and different parts of the plants had significant effects on the nutrient composition and total energy parameters $(p<0.05$; Figure 2$)$. The crude protein $(15.98-16.22 \%)$ and fat contents (8.78-15.52\%) of the fruits (Fdf, Fhf, and Agf) were higher than those of the umbels, stalks, and roots. Moreover, the fruits had the highest concentration of phosphorus (0.59-0.65\%) and total energy values (22.97-24.50 MJ/kg); however, they had lower NDF, ADF, and ash contents. The level of phosphorus of fruits from dill and fennel observed in this study was higher than that of a report by a previous similar study (0.1745-0.3285\%) [26]. The level of crude protein and ADF of Fdf and Fhf was consistent with the previous report from fennel fruits (15\% crude protein and $24 \%$ ADF) [14]. Stalks and roots (except for Fdr) exhibited the highest NDF and ADF contents, followed by the umbels and fruits. The umbels contained more ash (9.66-18.66\%) than the other parts. Total ash content could be an indicator of the total mineral content in the plant materials. In this context, it can be inferred that Fdu contained the highest amount of minerals. Agu contained the highest amount of calcium $(0.31 \%)$, and the lowest amount was found in Ags (0.11\%).

Plants are a good source of nutritional components, such as fiber, minerals, and proteins, for humans and other animals. According to the U.S. Department of Agriculture, fennels are rich in dietary fiber and vitamins, relative to human needs [18]. Foeniculum vulgare contains appreciable amounts of minerals, especially potassium, followed by calcium, manganese, sodium, and iron [27]. Nevertheless, the nutrient composition can vary substantially between members of the Apiaceae family, depending on their genetic structure, soil type, and location; this can also vary depending on the plant part analyzed [28]. Therefore, measuring the nutritional composition of different parts and species of fennel and dill is of great significance in the view of the comprehensive utilization of such plants. 

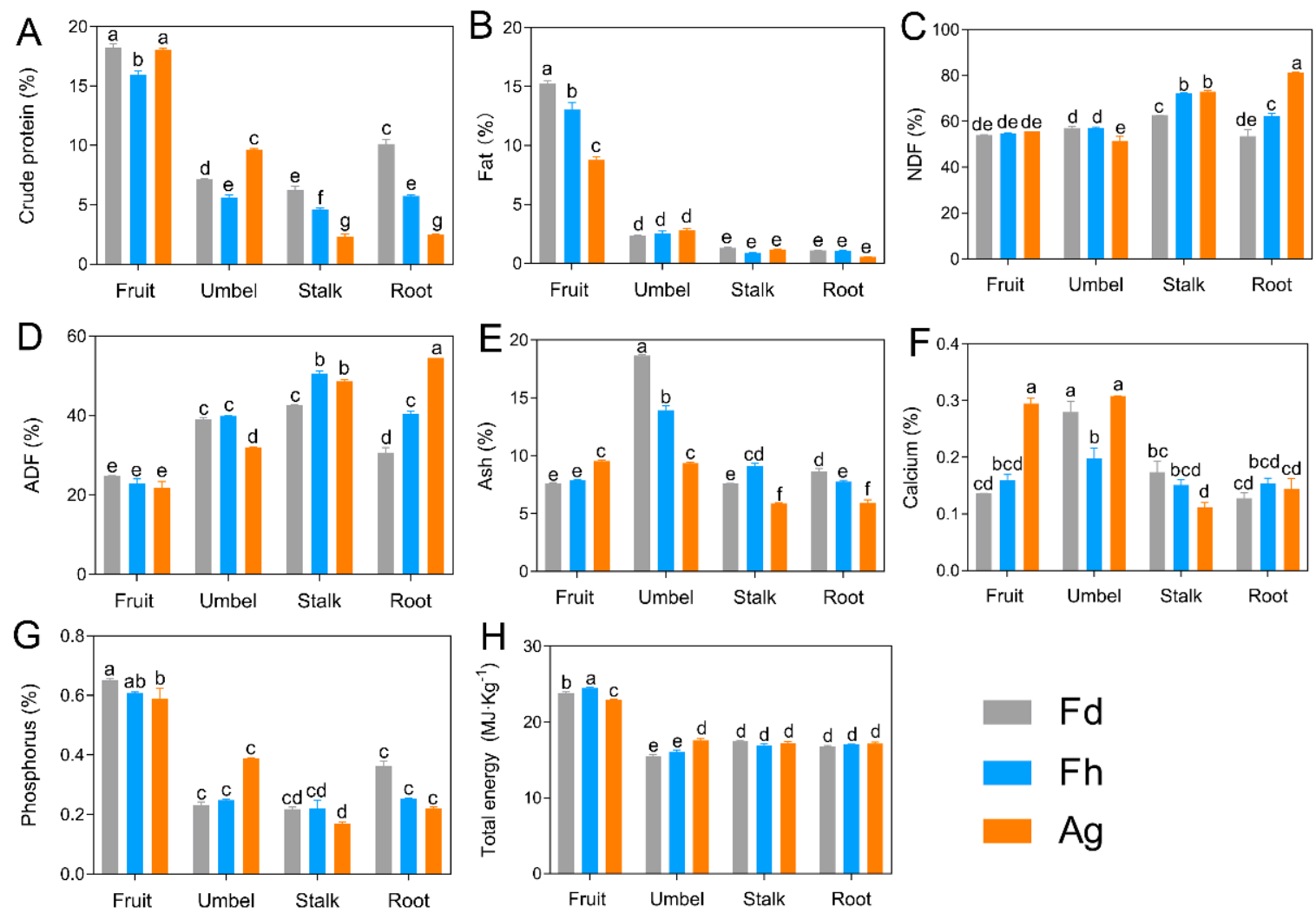

\section{$\mathrm{Fd}$ \\ $\mathrm{Fh}$ \\ Ag}

Figure 2. Nutritional composition $(\mathbf{A}-\mathbf{G})$ and total energy $(\mathbf{H})$ of fruits, umbels, stalks, and roots from three Apiaceae species. Acid detergent fiber (ADF) and neutral detergent fiber (NDF); Foeniculum vulgare "Dwarf" (Fd), F. vulgare "High" (Fh), Anethum graveolens (Ag). Different letters indicate significant differences $(p<0.05)$.

\subsection{Comparison of EO Yields from Different Samples}

EOs can be extracted from all parts of Fd, Fh, and Ag. The evaluation of EO yields, shown in Figure 3, indicated significant differences $(p<0.05)$ between the varieties and parts. These values ranged from $0.04-3.90 \% v / w$ (dry matter). The lowest EO yields were obtained in the stalks and roots $(<0.2 \% v / w)$, and the highest EO yield was obtained in the fruits $(\geq 2 \% v / w)$. The EO yields of fruits from Fd, Fh, and Ag were $2 \% v / w, 2.9 \% v / w$, and $3.9 \% v / w$, respectively. The EO yield of Fhf was similar to that of a previous study about fennel fruit $(\sim 3 \% v / w)$ [29]. Meanwhile, the EO yield of Agf was higher than a previous study about dill fruit by different hydrodistillation techniques $(<4 \% v / w)$ [30]. Umbels (Fdu, Fhu, and Agu) across all the samples provided intermediate EO yields ( $0.35 \%)$. Interestingly, the $\mathrm{EO}$ yield of $\mathrm{Fd}$ fruits was lower than that of $\mathrm{Fh}$ and $\mathrm{Ag}$, but the EO yield of the stalks and roots of Fd was higher than that of Fh and Ag.

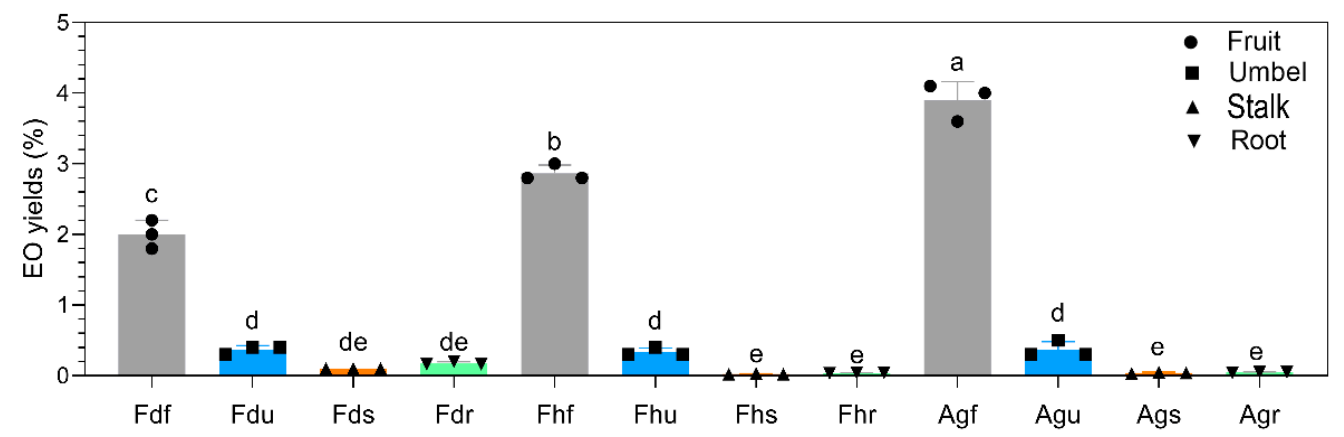

Figure 3. The evaluation of EO yields of all samples. Different letters indicate significant differences $(p<0.05)$. 
In the Apiaceae family, the accumulation of EOs is delimited to specialized structures located along with the vegetative and reproductive organs of plants, known as secretory ducts (or oil ducts) and vittae, respectively [31]. In the present study, the fruits provided the highest EO yield, which might be explained by the storage of oil in the oil ducts in fruits, as shown in Figure 1. In the EO extraction process, as the oil duct structures ruptured, the surface area and permeability of cells increased after grinding. This was conducive to the extraction of EOs and increased the EO yields [32]. Different ecological functions may be reflected in the EO content differences between different plant parts. In general, Apiaceae fruits, which contain reproductive organs, are optimum sources of biologically active compounds, regardless of the recovery rate or relative amounts [2]. The substantial difference in the EO yields between fennel and dill fruits could be explained by the "allocation strategy." Dill "invests" more than fennel in the accumulation of dry matter in biomass and fruits, stretching the yield potential of each individual plant to the maximum level [33]. In addition, the content and quality of Apiaceae EOs are closely related to season, harvest time, climate, soil, and irrigation [34]. For instance, the optimal harvest time for dill in terms of maximizing the EO yield is at dawn, when a plant is fully growing, and the flower buds are fully open [8]. This coincides with the harvest time (at dawn) of this study.

\subsection{Comparison of EO Constituents}

In this study, twenty-six compounds were identified, accounting for $97.71-99.63 \%$ of the total EO components, and the composition of the EOs varied greatly among parts and species. Heatmap analysis further visualized the differences in detail (Table 1; Figure 4A). Our results showed that two or three components of EOs exhibited relatively high proportions, and the remaining components usually existed at trace levels. Estragole was the dominant component $(>80 \%)$ in the fruits of Fdf and Fdu. Anethole was the dominant component $(>70 \%)$ in the EOs of Fhf and Fhu. Estragole and anethole have also been reported as the main components in the EOs of fennel fruit; their average composition was 34.90 and $56.81 \%$, respectively [35]. Agf EOs contained the highest levels of limonene $(50.19 \%)$ and carvone (42.41\%). Karimi et al. [36] previously reported that limonene and carvone in the EOs of dill seed occupied 3.66 and $26.48 \%$, respectively. Carvone and apiole in the EOs of Agu accounted for 45.78 and $23.83 \%$ of the total EO components, respectively. Distinctively, apiole was the main component in the roots of $\mathrm{Fd}$, Fh, and $\mathrm{Ag}$, accounting for $92.85,94.24$, and $67.13 \%$, respectively. The contents of dill ether, $\alpha$-phellandrene, and p-cymene in Ags EOs accounted for 28.50, 28.44, and 25.67\%, respectively. The previous study reported leaves and stems from fennel having higher $\alpha$-phellandrene content $(>15 \%)$, while the levels were minimal in the seeds [37]. This was similar to the current results, where $\alpha$-phellandrene was only detected in Fhs EOs (stems) from fennel samples. Interestingly, the content of $\alpha$-phellandrene of EOs from Ags in this work was also found to be highest among all samples. Overall, estragole, anethole, apiole, carvone, and limonene were the main chemical components of $\mathrm{Fd}$, Fh, and $\mathrm{Ag}$. In terms of sample correlations, significant positive correlations were observed between Fdf and Fhf, followed by Fdu and Fhu, Fdr and Fhr, Fdu and Fdf, and Agf and Agu (Figure 4B). These samples have significant similarities in terms of chemical composition. Conversely, there were some negative correlations between samples, such as Fdr and Ags, Fhr and Ags. The results suggest that our samples can be distinguished based on their chemical composition. 
Table 1. Chemical compositions of essential oils derived from different parts of fennel and dill.

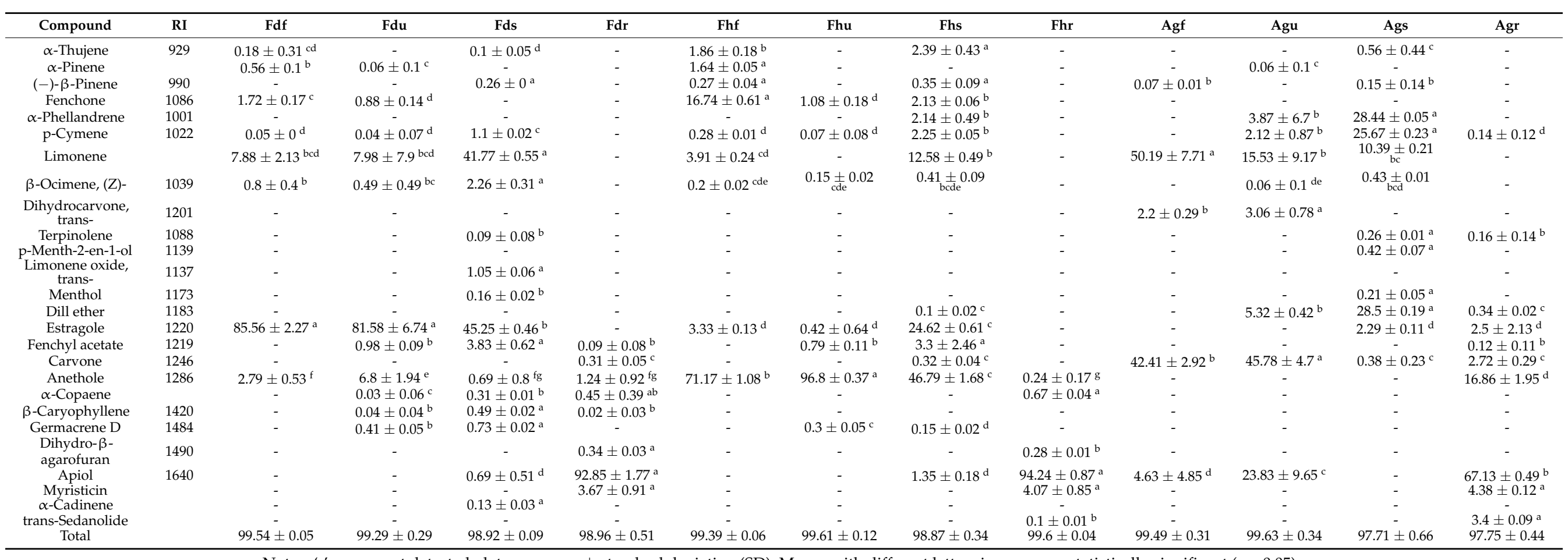

Notes: '-' means not detected; data are mean \pm standard deviation (SD); Means with different letters in a row are statistically significant $(p<0.05)$. 


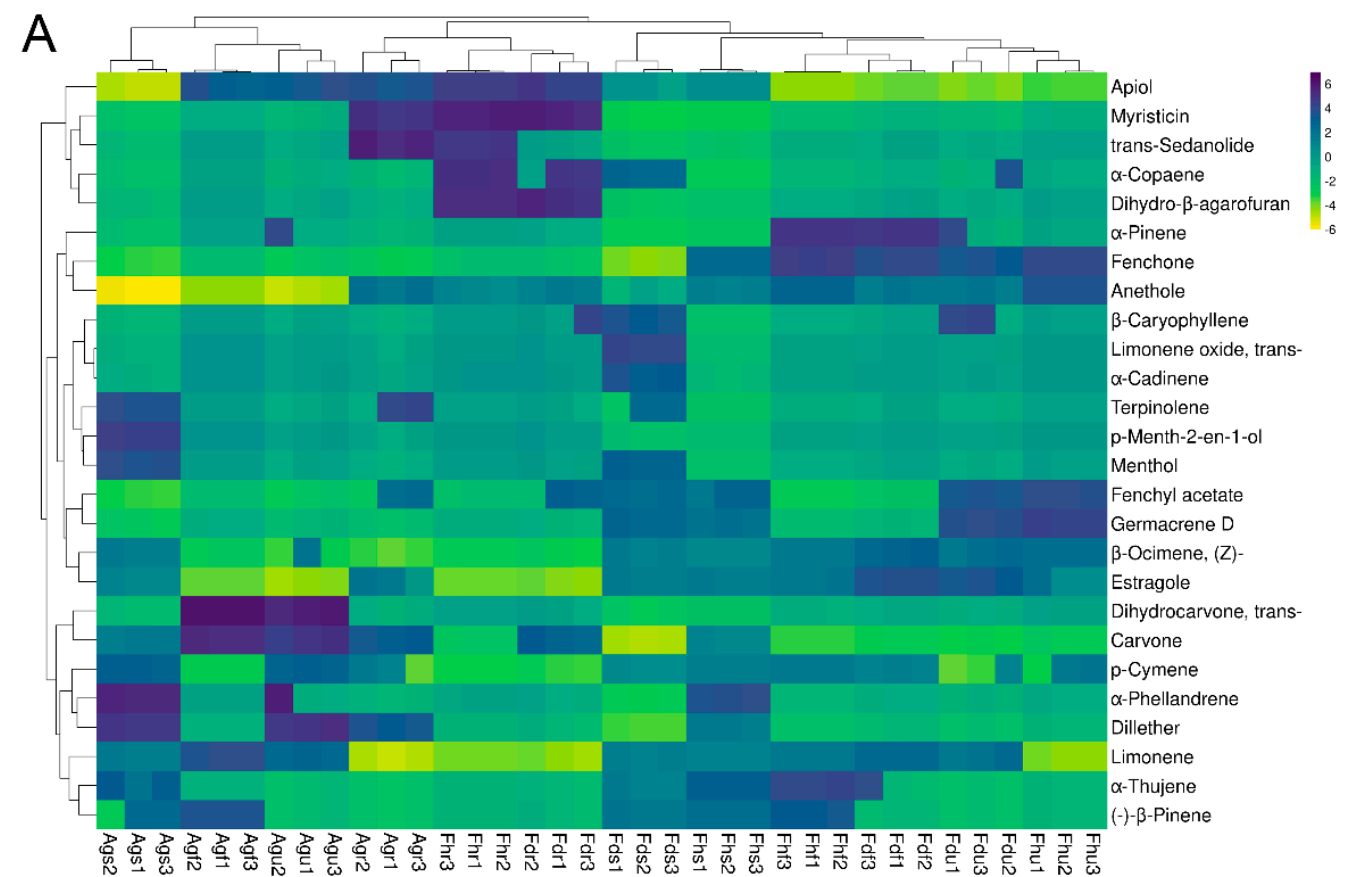

B

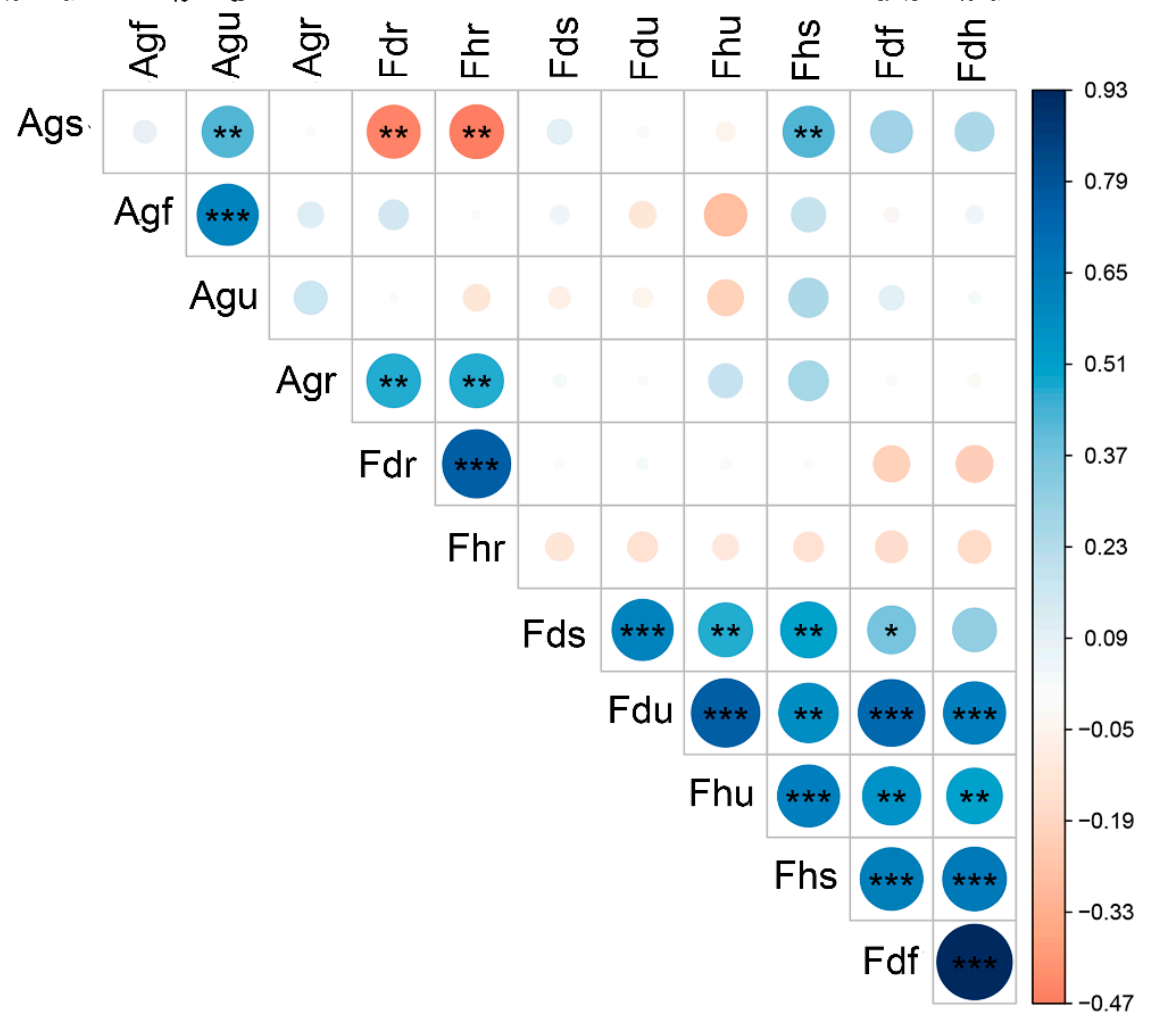

Figure 4. Heatmap (A) and Spearman rank correlation plot (B) based on EO chemical profiling. $\left({ }^{*} p<0.05,{ }^{* *} p<0.01\right.$, $* * *<0.001)$.

Moreover, an UpSet plot was obtained to visualize the distributions of shared and unique components of different parts and species (Figure 5A). The results revealed that the number of components present in each EO type ranged from 5 to 16 . Of these, the majority of components were shared among multiple species. For instance, anethole was present in all fennel samples, and similarly, estragole was found in all fennel samples, except for the 
root samples. Carvone was present in different parts of $\mathrm{Ag}$, and its content was higher in Agf and Agu than in Ags and Agr. Myristicin was unique to the roots of Fh, Fd, and Ag. Interestingly, the EO yield of the stalks was low; however, more components were identified in the stalks than in the other parts. Three components, limonene oxide (Fds), trans- $\alpha$ cadinene (Fds), and p-menth-2-en-1-ol (Ags), were unique to specific species (Figure 5B). The aforenoted results provide new insights on the shared and unique components among different plant species and plant parts.

A

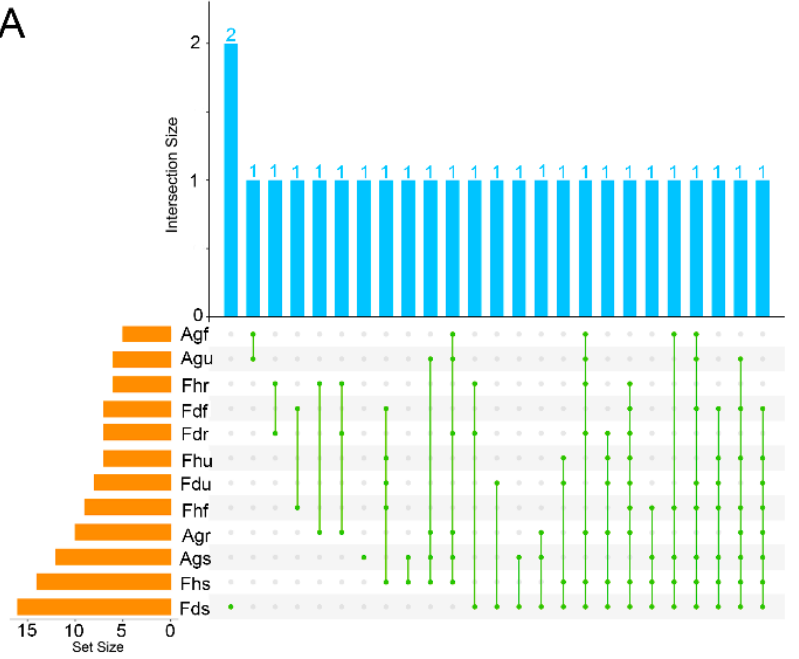

B

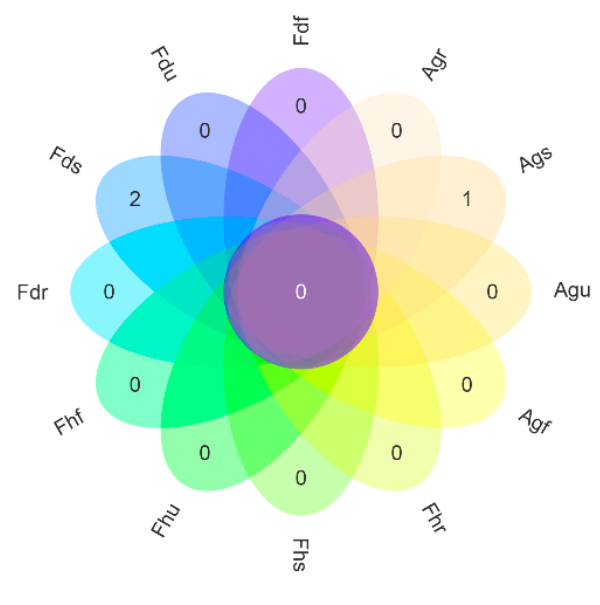

Figure 5. UpSet plot (A) and Venn diagram (B) based on the amounts of chemical components in EOs.

\subsection{Multivariate Statistical Analysis of EO Chemical Profiles}

To further classify the EOs in the fruits, umbels, stalks, and roots from the three species (Fd, Fh, and Ag), two PCA plots were constructed based on the species and different parts, respectively (Figure 6A,B). Overall, an improved classification was obtained based on the species than that based on the parts, except for the roots. Similarly, dendrogram analysis of EO chemical profiles yielded four main groups. Notably, the roots of different species were clustered into one group, and the samples of other parts were clustered into three other groups based on the species (Figure 6C). These results indicate that the components in the roots of the three cultivars exhibited more similar trends than those in the other parts, whereas the aerial parts (fruits, umbels, and stalks) of a specific species exhibited a similar EO composition. The EO chemical profiles of the roots were significantly different from those of the aerial parts. This may be because the roots were buried in the soil, leading to a significantly different growth environment from that of the aerial parts. The chemical compositions of EOs in the fruits, umbels, and stalks of a species are more similar than those in the same plant parts of different species, which might be explained based on the genotype. Yaldiz and Camlica [38] evaluated the chemical composition, mineral content, and antioxidant effect of 46 types of fennel plants and found significant differences between different fennel genotypes. 
A

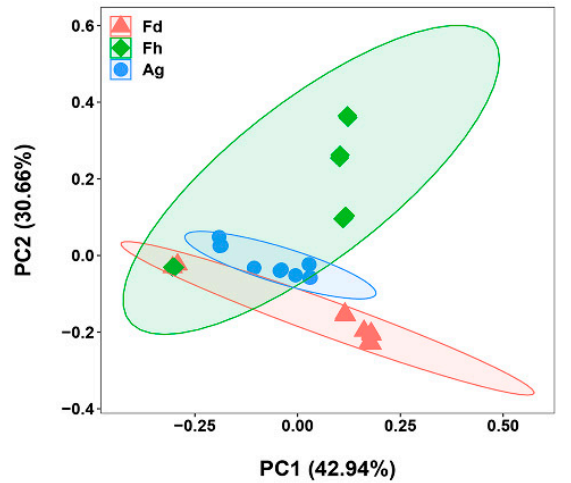

B

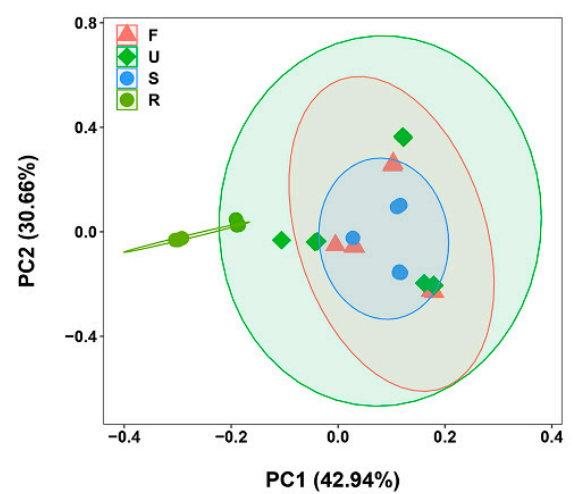

D

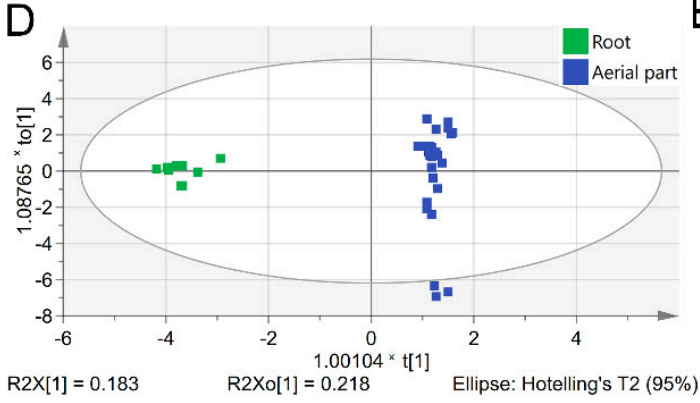

F

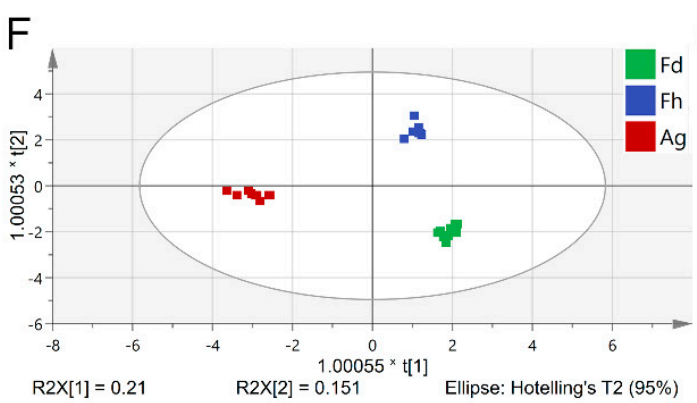

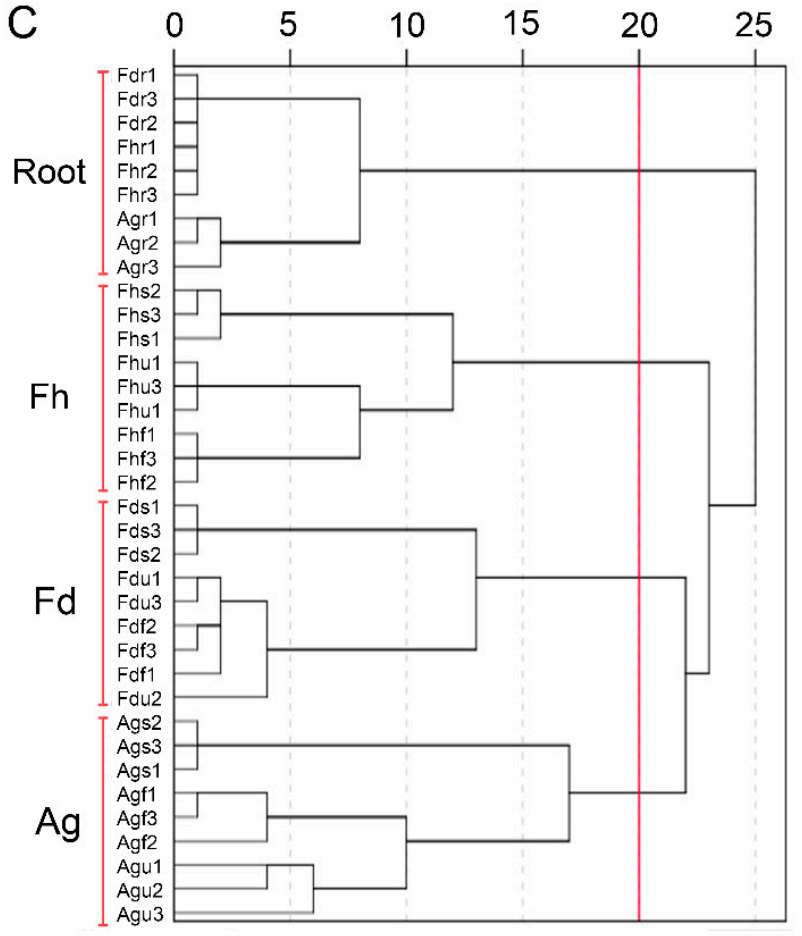

E
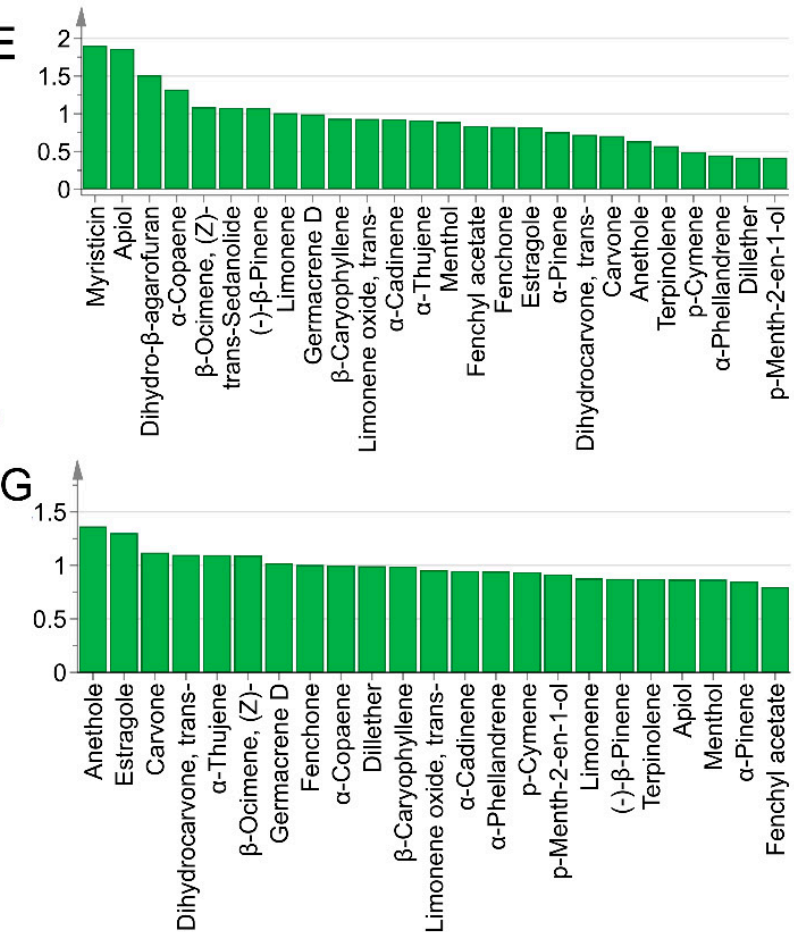

Figure 6. PCA map (A,B), dendrogram (C), score plots (D), and VIP values (E) from OPLS-DA analysis based on the chemical profiles of roots and aerial parts. Score plots (F) and VIP values (G) from OPLS-DA analysis based on the chemical profiles of three species (except for the roots).

According to the dendrogram analysis results (Figure 6C), a supervised OPLS-DA statistical method was further used to distinguish the EO components between roots and aerial parts (Figure 6D,E) and among the aerial parts of the different species, $\mathrm{Fd}$, Fh, and $\mathrm{Ag}$ (Figure 6F,G). The variable importance in projection (VIP) values of the PLS-DA model were used to screen chemical markers and to determine the contribution of chemical components 
to the PLS-DA model [39]. Figure 6E shows the VIP values of each EO component, and the vital components were identified (VIP value $\geq 1$ ). Of these, myristicin (1.90399) and apiol (1.85922) significantly contributed to the classification via the OPLS-DA model; thus, these may be appropriate chemical markers to distinguish the EOs from the root and aerial parts of fennel or dill. As reported previously, myristicin and apiol are typical components of EOs isolated from Apiaceae roots [2], while anethole (1.36571), estragole (1.30292), and carvone (1.11947) may be appropriate chemical markers for distinguishing the EOs of aerial parts from $\mathrm{Fd}$, Fh, and $\mathrm{Ag}$.

In addition, EO chemical profiles may vary substantially between parts of the same plant species [40]. In particular, the composition of EOs varied between the root and aerial parts of Fd, Fh, and Ag. Interestingly, the EO chemical profile of the Apiaceae family is particularly different from that of the aerial parts and roots of Cuminum cyminum L. [41], Daucus muricatus L. [42], and Thapsia villosa L. [43]. Notably, 115 compounds were found in the aerial parts of Carpesium cernuum EOs, whereas only 37 compounds were found in the roots, which is consistent with previous studies. The proportions of the main compounds also vary greatly; for example, $\alpha$-pinene $(35 \%)$ and 2,5-dimethoxy-p-cymene $(12 \%)$ were the predominant compounds in the EOs of shoots, whereas 2,5-dimethoxy-p-cymene (55\%) and thymol isobutyrate ( $9 \%$ ) were predominant in the EOs of roots [44].

\section{Conclusions}

In conclusion, this study provides fundamental information regarding the nutritional composition and EO profiles of fennel and dill. Multivariate statistical analysis showed that EOs extracted from root parts were significantly different from those obtained from the other parts. Some potential chemical markers (i.e., myristicin and apiol) were identified for distinguishing the arterial parts (fruits, umbels, and stalks) and roots of fennel and dill. Anethole, estragole, and carvone were identified as vital chemical markers for differentiating the plant species $\mathrm{Fa}, \mathrm{Fd}$, and Ag. These results provide a new understanding of the chemical characteristics of different parts of fennel and dill, which is significant for the efficient utilization of fennel and dill as food additives. In the future, to fully utilize the medical and nutritional properties of fennel and dill, the determination of specific chemical compositions from different parts and species is essential. Accordingly, we suggest that fruits are a good source of EOs, and also can be a source of further compounds with food additive relevance, of which the biological activity is worth further exploration. Umbels act as an important by-product of fennel and dill, whose EOs and minerals should be efficiently utilized and worth exploring. Furthermore, stalks have a large biomass and can be used as feed additives, whose nutritional compositions should be further explored. Taken together, the consumption of umbels and stalks would also reduce the amount of waste produced annually from the global food industry.

Author Contributions: Conceptualization, Y.H. and J.K.; methodology, Y.H.; software, J.K.; validation, R.Y., J.L. and L.S.; formal analysis, X.G.; investigation, Y.C.; resources, Y.C.; data curation, Y.H.; writing—original draft preparation, Y.H.; writing—review and editing, J.L. and L.S.; visualization, J.K.; supervision, L.S.; project administration, J.L.; funding acquisition, L.S. All authors have read and agreed to the published version of the manuscript. Authorship must be limited to those who have contributed substantially to the work reported.

Funding: This research was funded by "the Strategic Priority Research Program of the Chinese Academy of Sciences (Grant No. XDA26040306)"; and "the National Wild Plant Germplasm Resource Center".

Institutional Review Board Statement: Not applicable.

Informed Consent Statement: Not applicable.

Data Availability Statement: Not applicable.

Acknowledgments: We thank Lu Wang, from the Plant Science Facility of the Institute of Botany, Chinese Academy of Sciences, for her excellent technical assistance of mass spectrum analysis. 
Conflicts of Interest: The authors declare no conflict of interest.

\section{References}

1. Sayed-Ahmad, B.; Talou, T.; Saad, Z.; Hijazi, A.; Merah, O. The Apiaceae: Ethnomedicinal Family as Source for Industrial Uses. Ind. Crop. Prod. 2017, 109, 661-671. [CrossRef]

2. Sousa, R.M.O.F.; Cunha, A.C.; Fernandes-Ferreira, M. The Potential of Apiaceae species as Sources of Singular Phytochemicals and Plant-Based Pesticides. Phytochemistry 2021, 187, 112714. [CrossRef]

3. Gautam, P.; Singh, K.; Kalra, S.; Khanna, D.; Paliwal, Y.K.; Mehan, S. Dill Herb: Wall Against Dysfunctions: An Updated Profile. Int. J. Recent Adv. Pharm. Res. 2013, 4, 1-8.

4. Rostaei, M.; Fallah, S.; Lorigooini, Z.; Abbasi Surki, A. The Effect of Organic Manure and Chemical Fertilizer on Essential Oil, Chemical Compositions and Antioxidant Activity of Dill (Anethum graveolens) in Sole and Intercropped with Soybean (Glycine max). J. Clean. Prod. 2018, 199, 18-26. [CrossRef]

5. Ghanem, M.T.M.; Radwan, H.M.A.; Mahdy, E.S.M.; Elkholy, Y.M.; Hassanein, H.D.; Shahat, A.A. Phenolic Compounds from Foeniculum vulgare (subsp. Piperitum) (Apiaceae) Herb and Evaluation of Hepatoprotective Antioxidant Activity. Pharmacogn. Res. 2012, 4, 104-108. [CrossRef]

6. Javed, R.; Hanif, M.A.; Ayub, M.A.; Rehman, R. Chapter 19. Fennel. In Medicinal Plants of South Asia; Hanif, M.A., Nawaz, H., Khan, M.M., Byrne, H.J., Eds.; Elsevier: Amsterdam, The Netherlands, 2020; pp. 241-256.

7. Miraj, S.; Kiani, S. Study of Antibacterial, Antimycobacterial, Antifungal, and Antioxidant Activities of Foeniculum vulgare: A Review. Pharm. Lett. 2016, 8, 200-205.

8. Mohsin, M.M.; Hanif, M.A.; Ayub, M.A.; Bhatti, I.A.; Jilani, M.I. Chapter 18. Dill. In Medicinal Plants of South Asia; Hanif, M.A., Nawaz, H., Khan, M.M., Byrne, H.J., Eds.; Elsevier: Amsterdam, The Netherlands, 2020; pp. 231-239.

9. Özcan, M.M.; AhmetÜnver, T. Mineral Content of Some Herbs and Herbal Teas by Infusion and Decoction. Food Chem. 2008, 3 , 1120-1127. [CrossRef]

10. Lillian, B.A.; Carvalho, A.M.; Ferreira, I.C. The Nutritional Composition of Fennel (Foeniculum vulgare): Shoots, Leaves, Stems and Inflorescences. LWT Food Sci. Technol. 2010, 43, 814-818. [CrossRef]

11. Özcan, M.M.; Akbulut, M. Estimation of Minerals, Nitrate and Nitrite Contents of Medicinal and Aromatic Plants Used as Spices, Condiments and Herbal Tea. Food Chem. 2008, 106, 852-858. [CrossRef]

12. Fadlalla, I.M.T.; Omer, S.A.; Atta, M. Determination of Some Serum Macroelement Minerals Levels at Different Lactation Stages of Dairy Cows and Their Correlations. Sci. Afr. 2020, 8, e00351. [CrossRef]

13. Saeedi, S.; Dayani, O.; Tahmasbi, R.; Khezri, A. Effect of Supplementation of Calf Starter with Fennel Powder on Performance, Weaning Age and Fermentation Characteristics in Holstein Dairy Calves. J. Anim. Physiol. Anim. Nutr. 2017, 101, 81-87. [CrossRef] [PubMed]

14. Hajalizadeh, Z.; Dayani, O.; Khezri, A.; Tahmasbi, R.; Mohammadabadi, M.R. The Effect of Adding Fennel (Foeniculum vulgare) Seed Powder to the Diet of Fattening Lambs on Performance, Carcass Characteristics and Liver Enzymes. Small Rumin. Res. 2019, 175, 72-77. [CrossRef]

15. Rao, J.J.; Chen, B.C.; McClements, D.J. Improving the Efficacy of Essential Oils as Antimicrobials in Foods: Mechanisms of Action. Annu. Rev. Food Sci. Technol. 2019, 10, 365-387. [CrossRef]

16. Aghbash, B.N.; Pouresmaeil, M.; Dehghan, G.; Nojadeh, M.S.; Mobaiyen, H.; Maggi, F. Chemical Composition, Antibacterial and Radical Scavenging Activity of Essential Oils from Satureja macrantha C.A.Mey. at Different Growth Stages. Foods 2020, 9,494 [CrossRef]

17. Falleh, H.; Ben Jemaa, M.; Saada, M.; Ksouri, R. Essential Oils: A Promising Eco-Friendly Food Preservative. Food Chem. 2020, 330, 127268. [CrossRef]

18. Badgujar, S.B.; Patel, V.V.; Bandivdekar, A.H. Foeniculum vulgare Mill: A Review of Its Botany, Phytochemistry, Pharmacology, Contemporary Application, and Toxicology. BioMed. Res. Int. 2014, 2014, 842674. [CrossRef] [PubMed]

19. Wright, J. The Herb Society of Americas Essential Guide to Dill; American Press: Lake Charles, LA, USA, 2010.

20. Hartmans, K.J.; Diepenhorst, P.; Bakker, W.; Gorris, L.G.M. The Use of Carvone in Agriculture: Sprout Suppression of Potatoes and Antifungal Activity against Potato Tuber and Other Plant Diseases. Ind. Crops Prod. 1995, 4, 3-13. [CrossRef]

21. Sun, J. D-Limonene: Safety and Clinical Applications. Altern. Med. Rev. 2007, 12, 259-264. [PubMed]

22. Vieira, A.J.; Beserra, F.P.; Souza, M.C.; Totti, B.M.; Rozza, A.L. Limonene: Aroma of Innovation in Health and Disease. Chem. Biol. Interact. 2018, 283, 97-106. [CrossRef]

23. AOAC. Official Methods of Analysis, 17th ed.; Association of Official Analytical Chemists Inc.: Arlington, VA, USA, 2002.

24. Van Soest, P.J.; Robertson, J.B.; Lewis, B.A. Methods for Dietary Fiber, Neutral Detergent Fiber, and Nonstarch Polysaccharides in Relation to Animal Nutrition. J. Dairy Sci. 1991, 74, 3583-3597. [CrossRef]

25. Babushok, V.I.; Linstrom, P.J.; Zenkevich, I.G. Retention Indices for Frequently Reported Compounds of Plant Essential Oils. J. Phys. Chem. Ref. Data. 2011, 40, 043101. [CrossRef]

26. Özcan, M. Mineral contents of some plants used as condiments in Turkey. Food Chem. 2004, 84, 437-440. [CrossRef]

27. Bukhari, H.; Shehzad, A.; Saeed, K.; Butt, M.; Tanweer, S.; Iftikhar, T.; Din, U. Compositional Profiling of Fennel Seed. Pak. J. Food Sci. 2014, 24, 132-136. 
28. Tunçtürk, M.; Özgökçe, F. Chemical Composition of Some Apiaceae Plants Commonly Used in Herby Cheese in Eastern Anatolia. Turk. J. Agric. For. 2015, 39, 55-62. [CrossRef]

29. Rezaei-Chiyaneh, E.; Amirnia, R.; Amani Machiani, M.; Javanmard, A.; Maggi, F.; Morshedloo, M.R. Intercropping fennel (Foeniculum vulgare L.) with common bean (Phaseolus vulgaris L.) as affected by PGPR inoculation: A strategy for improving yield, essential oil and fatty acid composition. Sci. Hortic. 2020, 261, 1089581. [CrossRef]

30. Stanojević, L.P.; Radulović, N.S.; Djokić, T.M.; Stanković, B.M.; Ilić, D.P.; Cakić, M.D.; Nikolić, V.D. The yield, composition and hydrodistillation kinetics of the essential oil of dill seeds (Anethi fructus) obtained by different hydrodistillation techniques. Ind. Crop. Prod. 2015, 65, 429-436. [CrossRef]

31. Franz, C.; Novak, J. Sources of Essential Oils. In Handbook of Essential Oils: Science, Technology, and Applications; Baser, K.H.C.K., Buchbauer, G., Eds.; CRC Press: Boca Raton, FL, USA, 2009; pp. 39-82.

32. Stankovic, M.; Stanojevic, L.; Nikolic, N.; Cakic, M. The Effect of Parsley (Petroselinum crispum (Mill.) Nym. ex A.W. Hill) Seeds Milling and Fermentation Conditions on Essential Oil Yield and Composition. Chem. Ind. Chem. Eng. Q. 2005, 11, 177-182. [CrossRef]

33. Carrubba, A.; Torre, R.; Saiano, F.; Aiello, P. Sustainable Production of Fennel and Dill by Intercropping. Agron. Sustain. Dev. 2008, 28, 247-256. [CrossRef]

34. Olle, M.; Bender, I. The Content of Oils in Umbelliferous Crops and Its Formation. Agron. Res. 2010, 8, 687-696.

35. El-Serafy, R.S.; El-Sheshtawy, A.A. Effect of nitrogen fixing bacteria and moringa leaf extract on fruit yield, estragole content and total phenols of organic fennel. Sci. Hortic. 2020, 265, 109209. [CrossRef]

36. Karimi, K.; Ahari, A.B.; Weisany, W.; Pertot, I.; Vrhovsek, U.; Arzanlou, M. Funneliformis mosseae root colonization affects Anethum graveolens essential oil composition and its efficacy against Colletotrichum nymphaeae. Ind. Crop. Prods. 2016, 90, 126-134. [CrossRef]

37. Guillen, M.D.; Manzanos, M.J. A study of several parts of the plant Foeniculum vulgare as a source of compounds with industrial interest. Food Res. Int. 1996, 29, 85-88. [CrossRef]

38. Yaldiz, G.; Camlica, M. Variation in the Fruit Phytochemical and Mineral Composition, and Phenolic Content and Antioxidant Activity of the Fruit Extracts of Different Fennel (Foeniculum vulgare L.) Genotypes. Ind. Crop. Prod. 2019, 142, 111852. [CrossRef]

39. Hu, G.; Peng, X.; Gao, Y.; Huang, Y.; Li, X.; Su, H.; Qiu, M. Effect of Roasting Degree of Coffee Beans on Sensory Evaluation: Research from the Perspective of Major Chemical Ingredients. Food Chem. 2020, 331, 127329. [CrossRef]

40. Baser, K.H.C.; Kırımer, N. Essential Oils of Anatolian Apiaceae-A Profile. Nat. Volatiles Essent. Oils. 2014, 1, 1-50.

41. Bettaieb, I.; Bourgou, S.; Wannes, W.A.; Hamrouni, I.; Limam, F.; Marzouk, B. Essential Oils, Phenolics, and Antioxidant Activities of Different Parts of Cumin (Cuminum Cyminum, L.). J. Agric. Food Chem. 2010, 58, 10410-10418. [CrossRef] [PubMed]

42. Bendiabdellah, A.; Dib, M.E.; Djabou, N.; Allali, H.; Tabti, B.; Muselli, A.; Costa, J. Biological Activities and Volatile Constituents of Daucus muricatus L. from Algeria. Chem. Cent. J. 2012, 6, 10. [CrossRef]

43. Drew, D.P.; Rasmussen, S.K.; Avato, P.; Simonsen, H.T. A Comparison of Headspace Solid-Phase Microextraction and Classic Hydrodistillation for the Identification of Volatile Constituents from Thapsia spp. Provides Insights into Guaianolide Biosynthesis in Apiaceae. Phytochem. Anal. 2012, 23, 44-51. [CrossRef]

44. Wajs-Bonikowska, A.; Malarz, J.; Szoka, Ł.; Kwiatkowski, P.; Stojakowska, A. Composition of Essential Oils from Roots and Aerial Parts of Carpesium cernuum and Their Antibacterial and Cytotoxic Activities. Molecules 2021, 26, 1883. [CrossRef] 